\title{
Will They Be Business Partners in the Digital Era? - On The Future Work and Roles of Controllers
}

\author{
Matthias D. Mahlendorf | Barbara E. Weißenberger
}

"It is difficult to make predictions, especially about the future." - this statement, which is alternately attributed to Winston Churchill, Mark Twain, or even Niels Bohr, also applies to the question of how the work and roles of controllers will change over the next decade. Until today, with more than 100.000 positions the controllers' function is paramount within the finance departments of German corporations (Grunwald-Delitz et al. 2014: 49). But as the digital transformation within the finance function has increasingly gathered speed in the last decade (e.g., Arnold 2018; Kokina and Davenport 2017; Vasarhelyi, Kogan and Tuttle 2015; Delen and Demirkan 2013), this raises a key question: How will the work and roles of controllers evolve in the wake of technological change and disruption. Where will the value contribution of accounting and controlling lie in a digitized world when traditional clerical tasks will increasingly be performed by powerful information technology and artificial intelligence (AI)? Or put provocatively: Do controllers belong to the occupational groups which, according to the much-cited study by Oxford economists Frey and Osborne (2017), will be rationalized away by digital technologies in twenty years time at the latest?

Prof. Dr. Matthias D. Mahlendorf | Professor of Managerial Accounting | Frankfurt School of Finance \& Management | m.mahlendorf@fs.de

Prof. Dr. Barbara E. Weißenberger / Lehrstuhl für BWL, insbes. Controlling und Accounting | Heinrich-Heine-Universität Düsseldorf | controlling@hhu.de 
Until today, this discussion to a large degree takes place during nonacademic conferences and lectures from leading practitioners ${ }^{1}$, in interfirm working groups ${ }^{2}$, and also in non-scientific journals ${ }^{3}$. Finance consulting firms add to this discussion by suggesting finance transformation roadmaps that typically imply a fundamental shift in controllers work environment as well as the technology used (Baldvinsdottir et al. 2010: 1). One of the digital tools suggested typically at the beginning of such a roadmap, is robotic process automation, which allows configuring accounting software to emulate human actions executing business processes in accounting and controlling. A step further is the introduction of predictive analytics systems is advocated that typically combine classical statistics, knowledge discovery from (big) data bases, and/or machine learning to improve financial forecasting. In the same vein, process mining tools use these technologies to extract knowledge from event logs to analyse and monitor business processes. Another area of the finance transformation roadmap is the use of self-service business intelligence that is supposed to provide managers with straightforward access to financial reports and visualisations tailored to their individual needs. Still, taking a closer look, the excitement at all these new possibilities is dimmed as the pilot use cases for these technologies are still in their very early stages (Grönke 2017: 8). It is thus still unclear to what extend they will really prove feasible and reap the practical benefits that are projected and, as a consequence, how controllers work and roles will change in the next decade.

Our paper therefore contributes by providing examples for the developments that we see in the field of controlling, thus joining the different threads of discussion in business practice together with the existing body of academic literature on controllers' work and roles to suggest some answers to the resulting questions: Will controllers have a future as managerial counterparts or will their jobs vanish akin to the jobs of, e.g., telephone operators, typists or business clerks? If they continue as a business function, will their jobs change, i.e., will they embrace new tasks, and, in this vein, will their roles undergo a significant change and how will this change look like?

Our paper is structured as follows. In section 2, we will provide a brief summary on the observed evolution of controllers' roles and jobs until the 2000 s as the starting point of our analysis. In section 3, we will give an overview on the changes in firms' competitive environment since the 2000s, which drive the need for controllers as a managerial support function in the first place and point out the resulting reactions. In section 4, we will discuss new digital technologies that are increasingly used for administrative purposes and allow for computerization of many tasks that have before been part of the controllers' tasks, like, e.g., collecting information, forecasting or providing management reports and analyses. We will further provide an analysis on what remains from the traditional controller's job profile and in section 5 we will discuss our vision on what it may look like in the future, and in how far this will accompanied by a change of roles.

See, e.g., the lectures of Luka Mucic, CFO at SAP, Frank Mastiaux, CEO at EnBW, or Henri Catenos, Director Finance at Robert Bosch, on digital transformation within the finance function on the Deutsche Betriebswirtschafter-Tag in 2019.

2 See, e.g., the Schmalenbach working groups "Digital Finance“ or „Digital Reporting“, or the ICV working groups „Digital CFO Agenda“ or „Big Data and Controlling“.

3 See, e.g., Controller Magazin, Controlling and Management Review, or Finance. 


\section{What have controllers' jobs and roles looked like in the past?}

Evidence of controllers' positions in German firms - mostly subsidiaries of U.S. firms - dates back until the early 1950s (Weber and Schäffer 1998: 299). Still, their function did not evolve until the 1970s, when increasing economic growth together with globalization resulted not only in divisionalized organizational structures, but also fuelled the need for controllers' as a new type of finance experts. Their tasks extended far beyond the traditional field of book-keeping and cost accounting and encompassed the use of a broad array of management control tools, like, e.g., planning and budgeting systems, internal reporting or performance management systems. Even though their 'trendy' denomination (Wagenhofer 2006: 1), had been borrowed from the English language, German controllers' work profile until today differs significantly from their controller counterparts in Anglo-American firms, who traditionally manage key transaction cycles, monitor assets, provide support for financial reporting purposes, or deal with issues in company taxation, liquidity management, bank relations and insurance (Weber and Schäffer 2008: 12; RoehlAnderson and Bragg 2005: 6). ${ }^{4}$

Until the 1980s, controllers generally placed themselves in a service role (Sathe 1982; Sathe 1983), maintaining financial databases and systems to extract information demanded by management for score-keeping, attention-directing and problem-solving purposes and thus acting as gatekeepers to financial information (Simons et al. 1954: 24-26). Not surprisingly, these activities were often labelled as, e.g., bean-counting, number-crunching or being a watchdog (Baldvinsdottir et al. 2009: 868; Granlund and Lukka 1998: 186; Newman et al. 1989: 136).

In the following years, controllers started to claim a more businessoriented role, with the objective to explicitly provide added value with respect to managerial decision-making and control purposes. Controllers subsequently positioned themselves as proactive internal advisors or even business partners in operational as well as strategic decision-making, thus actively contributing to the achievement of a firm's organizational goals (Wolf et al. 2015: 38; Davis and McLaughlin 2009: 35; Byrne and Pierce 2007: 469). In a seminal case study based on multiple interviews with controllers at this time, Lambert and Sponem (2012: 572-584) identify four types of controllers and their functions. On the one hand, they find evidence of (1) 'discrete' controllers serving local management as well as (2) 'safeguarding' controllers reporting to central management, but both with rather limited authority, thus still reflecting a service-oriented role. On the other hand, they also find controllers acting as (3) 'partners' i.e. supporting local management and providing relevant financial information for daily decision-making, as well as (4) 'omnipotent controllers', who are part of the firm's top management and thus play a key role in strategic financial decision-making.

\footnotetext{
4 In the following, unless otherwise noted, the term 'controller' and its functional as well
} as institutional attributes will be used in the German understanding. 
But even though literature thus points at the importance of controllers involvement in decision-making (Zoni and Merchant 2007), it is still equivocal with respect to the question whether this aspired transformation of the controllers' role as service provider to business partner has indeed taken place or whether it yet remains a myth or narrative for selfaffirmation (Goretzki et al. 2013; Burns and Baldvinsdottir 2005: 726; Hopper 1980: 409).

Within the last ten years, the accelerating digital transformation has put additional pressure on the controllers' function. New technologies especially in the field of machine learning and Al not only increasingly allow for the computerization of non-routine cognitive tasks, but also for a seemingly fast and effortless collection and analysis of big data resulting from a multitude of different sources outside the internal data collected within a firm's financial and managerial accounting systems. ${ }^{5}$ This gives rise to a new type of expert denoted as data scientist, who is also supposed to provide managerial decision support as business advisor on the implications of data for products, processes, and decisions in business, thus instigating competition to the traditional controllers' function (Davenport and Patil 2012: 73).

In their seminal study on the future of employment, Frey and Osbourne (2017: 269) arrive at the conclusion, that in the end only those jobs will survive the digital transformation that allow for a high degree of cognitive flexibility and adaptability. Thus, in the light of this new expertise the question remains, whether and how the controllers' job as well as their roles in business will change as to remain a relevant part of the firm's finance function, or whether their expertise and impact will be substituted by a combination of managerial business acumen, Al and data science. To provide an answer to this question, a closer look on the change of firm's competitive environment and therefore the managerial eco-system as a precedent framing controllers' work and role profile is necessary.

\section{How has firms' competitive environment as well as the managerial eco-system changed?}

Putting it in a nutshell, we have been observing tremendous shifts in firms' competitive environments during the last twenty years often coined with

5 The Oracle Autonomous Database, for example, is a family of self-driving, self-securing, and self-repairing cloud services (Oracle 2019: 2). Salesfore has developed Einstein, a smart customer relations management assistant, which can "automatically discover relevant insights, predict future outcomes, see recommendations in context, and even automate tasks and workflows" (Salesforce 2020: 1). C3 Al provides a comprehensive suite for developing, deploying, and operating large-scale Al applications to enhance firms' digital transformation, including predictive maintenance, energy management, inventory optimization, internet of things, and more (C3 Al 2020). 
the term VUCA - i.e., more volatile, uncertain, complex, and also ambiguous, thus putting immense pressure on managerial work (Bennett and Lemoine 2014: 312).

The most noticeable of these changes has been the aforementioned digital transformation, starting in the late 1990s with the fast spread of the internet, resulting in the first rise of new digital business models that mirrored the massive growth in the use and adoption of the internet. Even though the burst of the subsequent dot-com bubble in the year 2000 caused a brief hiatus, the market launch of Apple's iphone as the first marketable smartphone in 2007 triggered a further and until now unprecedented suite of new digital business models. Emerging firms as Amazon, Apple, Facebook, Netflix, or Uber rapidly disrupted longstanding market structures and even drove former industry giants like Quelle, Kodak or Nokia into oblivion. The main characteristics of this second wave of digital transformation were the (nearly) costless and real-time exchange of information between people as well as machines as well as the ubiquitous availability of all types of data. All this resulted in a drastic reduction of transaction costs, and, as a consequence, in an increasing fragmentation of firms' business ecosystems.

In the wake of digital transformation, the globalization of businesses that had picked up speed in the 1980s accelerated even more. As Thomas Friedman (2006) pointed out, the business world had become 'flat', i.e. a level playing field where regional boundaries did not matter anymore. Today, firms building up multi-stage supply chains as well as selling their products to customers all over the world is rather the norm than the exception.

Still, globalization has come at a price as political borders still exist and have even become more noticeable with increasing nationalism and populism in several countries striving for economic dominance and political hegemony. Thus, organizing global business activities is hampered not only by differences in cultural or religious conditions, but also by disparities in, e.g., national tax regimes, legal requirements, especially as the number of laws and regulations firms have to observe in their business activities is steadily increasing over time in many jurisdictions (e.g. Crain and Crain 2010: 46). The same applies to public expectations on responsible firm behaviour that are mirrored in the growing need for ecological sustainability. With Greta Thunberg and the Fridays for Future movement, the public awareness of climate change has boosted drastically and places high demands on firms to shape the scope of their activities and to implement sustainable business models to maintain societal legitimacy.

The comprehensive nature of these changes has had a strong impact on both the complexity as well as the dynamics of firms' competitive environment. First, the number of factors constituting this environment and interacting with each other has grown for most firms to create a chaotic environment, in which markets emerge, collide, split, evolve, and die (Weber and Tarba 2014: 5). Even short-term predictions have become difficult due to what is coined 'radical uncertainty', as firms' knowledge of the future is fluctuating, vague, and uncertain (Keynes 1937: 213) and can by no means be formalized in state descriptions with numeric probabilities. Second, as digital technologies allow for real-time data collection and exchange, transaction speed is accelerating and making business even more volatile as new knowledge is being applied faster, the number 
of new products and services is increasing, and innovation cycles are becoming shorter (Bayus 1994: 306).

Even though these changes in most cases do not directly result in an impact on day-to-day operations, it is the manager's job to address both complexity and change by structuring the organization and its business model appropriately. In sum, we observe three major trends that characterize how firms react to the challenges within their competitive environment and thus reshape the managerial eco-system: (1) Implementing digital platform strategies, (2) introducing agility into the organization and (3) extending financial objectives with non-financial sustainability goals. As controllers are supporting management in administrative tasks like planning and budgeting or performance monitoring as well in decisionmaking and control, these trends affect their work as well.

Digital platform strategies have become viable with the first launching of the internet, but as a majority have not taken off until the dissemination of smartphone use. In contrast to traditional linear business models that either transform resources into products or solve customer problems at hand, platforms create value by linking users, i.e., suppliers and/or customers (Stabell and Fjeldstad 1998: 415). As a result, users benefit because digital platforms facilitate interaction combined with network effects, i.e. transaction costs decrease with an increasing number of users. But providers of digital platforms profit as well: First, if the network effects are massive enough, they create entry barriers to other competitors so that entire markets coalesce around a single platform monopoly ('winner-takes-it-all'-markets). Second, digital platforms usually provide their service at (near) zero marginal cost, so scaling up the business yields increasing returns to scale. The financial success of platform strategies is mirrored in the change of profitability in the last 25 years. Before the mid1990 s, the top 10 percentile of companies had a return on equity of $25 \%$ or more. Afterwards, this relation dramatically changed. While the lower half of all companies did not improve return on equity, the upper half of companies did so tremendously. The mark to belong to the top 10 percentile increased to $100 \%$ of return on equity (Economist 2016). This development is mainly driven by companies that are able to provide a platform and to digitally scale up their operations which implies relatively low marginal costs and high profitability, if the customer base is sufficiently large.

The strongest digital disruptors, such as Google and Amazon combine platform value with cost benefits for the customer and improved customer experience (Wade et al. 2016: 1). Another prime example for the winnertakes-all concept is the ride-sharing market. Uber was founded in 2009. Since then, it has been making a loss in every year, with accumulated losses reaching $\$ 14$ billion in fall 2019 (Economist 2019a). While controllers are certainly used to the idea that a business opportunity requires some initial investment before it turns profitable, the fact that a company with $\$ 14$ billion losses can have a market capitalization of more than $\$ 46$ billion (Yahoo Finance 2019) seems strange to many. When Dieter Zetsche, the former CEO of Daimler announced that his company does not consider itself purely as an automobile manufacturer, but as a crosslinked provider of mobility solutions (Zetsche 2015), it became clear that the idea of providing platforms also started to get traction in the more traditional industries with their brick-and-mortar value chains.

This has a strong impact on controllers work as well, who have to adapt reporting routines and performance measures as well as risk management 
tools to this new type of business model as well (Weißenberger 2019: 18). For example, as marginal production costs decrease towards zero, traditional profit and/or cost measures, e.g., margins or variable costs per unit, are replaced by measures reflecting search engine optimization or tracking search engine advertising for marketing control purposes (Weber and Stein 2019: 23). As especially young platform firms get their financing from equity investors, forecasting cashflows becomes paramount (Kemper 2013: 49). Furthermore, controllers face new challenges when evaluating investment proposals. While many firms invest in digitalization, the break-even is often not clear. Less than $15 \%$ of firms are able to quantify the return on investment of their digitalization initiatives (Dörner and Meffert 2015: 4). Sometimes, it is not even clear how the investments will generate the future profit - will customers be willing to pay for the new services, or will the customer data be the source of new revenue?

Whereas the successful implementation of digital platform monopolies addresses complexity and dynamics in firms' competitive environment by allowing them to control the market to a great extent, making organizations agile deals with a firm's capabilities for rapid and flexible reactions to changing business conditions and disruptive developments as well as for developing innovative strategies to create value. Therefore, agile organisations continuously and systematically vary their products, processes, services, and structures, with the intensity and variety of these internal changes is high (Weber and Tarba 2018: 6). To achieve agility, both managers' leadership impact to set direction and align people and administrative efficiency to put together the necessary resources for strategy execution is crucial. As a result, agility permeates organizations as a whole, including, e.g., the finance function. Deutsche Post, for example, implements agile leadership principles in the accounting function. According to Adam Pradela, Executive Vice President Corporate Accounting \& Controlling, Deutsche Post had used a trial-and-error culture for the introduction IFRS 16 (Schäffer and Pradela 2018: 17), even though such an approach would by most people be associated with start-ups or tech companies. For controllers in large companies, this requires a change of the mind-set.

The third trend is extending financial objectives with non-financial sustainability goals. This is not only important to make the customers happy, who want to buy a "clean conscience", but also to detect business risks early on. According to some risk models, climate change may destroy up to $20 \%$ of company value. These risks are not limited to the oil and gas industry, but also affect insurance, chemical industry and goods and services (Economist 2019b). Controllers have to respond to this trend, for example by putting more weight on sustainability related KPIs, to transform the business processes towards more sustainability. For example, Hansgrohe, a German 'hidden champion' and global market leader for bathroom fittings, had integrated as early as 2011 sustainability scorecard into their management control system (Gänßlen and Frey 2013: 327). As in the last years, capital markets have become increasingly interested in sustainability performance as well, such measures have become part of the financial disclosure: In this vein, the global food company Danone has started to report carbon adjusted earnings per share in 2020 (Holger 2020). Covestro, a specialty chemicals company and spin-off from Bayer, has been using three performance metrics for all staff for many years (Core 
Volume Growth, Free Operating Cash Flow, and Return on Capital Employed) and is in 2020 now planning to introduce the absolute CO2 reduction as the fourth KPI (Toepfer 2020).

\section{What are the new technologies available for controllers' tasks within the finance function?}

The strong standing of controllers in Germany - who may not be popular for everybody within a firm, but whose professional opinions are typically respected - stems largely from the fact that they are gatekeepers for internal financial transparency. It is the controllers who understand best how firm profitability and other measures related to firm performance are calculated and subsequently analysed, thus providing a much-needed business transparency for managerial decision-making.

Still, to this end they are oftentimes and to a large degree of their time involved in repetitive and rather mundane tasks (Manutiu 2018: 6): For example, collecting data from different elements of the firm's information system architecture and manually integrating them using a multitude of Excel- and/or Access-files with Visual Basic (VB)-Scripts. The resulting database is then used as a basis for creating deviation analyses and waterfall charts, or making forecasts, with tools like trend extrapolation or exponential smoothing, oftentimes adjusting forecast figures for political considerations. Finally, reports are derived using graphical templates either provided by a business intelligence package or by other text processing and/or presentation software.

Today, several new types of digital technology radically change this part of controllers tasks: (1) Robotic process automation (RPA) as a process automation tool for clerical tasks within controlling, (2) predictive analytics systems using Al to forecast key financial indicators, (3) process mining as a machine-learning based tool to identify inefficiencies as well as performance drivers, and (4) self-service business intelligence (BI) allowing for individualized reporting designs adapted to specific managerial needs.

RPA describes a preconfigured software that mimics clerical work in the execution of standardized business processes, transaction or tasks in unrelated software systems. Using machine learning algorithms, RPA systems can be trained in a relatively short time to handle large amounts of heterogeneous input data from different sources, thus automating many administrative processes that until a few years ago had been seen as exclusive domain of human work. Use cases from different industries (Lueg 2019; Devarajan 2018: 13) document that RPA systems allow to create a virtual clerical workforce working $365 / 24 / 7$, thus relocating offshore back-office processes away from shared services centres to which they were transferred in the first place to take advantage of cheaper labor. Other advantages related to RPA (McCann 2016: 38) are increased quality (e.g., accuracy, consistency, reliability) and reduced costs - a case 
study at Telefonicá 02 mentions a payback period for their investment in RPA of 12 months and a 3-year ROI between 650 and $800 \%$ (Lacity et al. 2015: 4). Technological advancements associated with RPA in the near future is a growing capability to process unstructured data, i.e. data that is not based on a pre-defined data-model or organized in a pre-defined manner, or the integration of natural language processing to enhance human interaction in increasingly complex and differentiated processes (Devarajan 2018: 17).

Predictive analytics systems is a collective term for data-based inference methodology, applying advanced methods of either symbolic Al, i.e., trying to simulate conscious reasoning by using an explicitly represented language to extract information from a given data set, or connectionist Al, i.e., employing machine learning with deep neural networks to identify meaningful patterns without an explicit representation scheme (Bolander 2019: 854), to forecast relevant key performance indicators for managerial decision-making (Blackburn et al. 2015: 411). In contrast to traditional statistical forecasting software predictive analytics software is not only to integrate internal financial and non-financial data, but also use big data from outside sources to enhance forecast accuracy in spite of increasing volatility and uncertainty. This holds especially for predictive analytics systems using deep neural networks to identify forecast patterns that had not been captured before. A use case is provided by Deutsche Post AG, who uses a combination of internal process data and external data sources, e.g., on weather data, to predict monthly revenues.

In this vein, predictive analytics, is about to revolutionize the budgeting process. In April 2019, BASF has replaced the annual bottom up forecast of the operating divisions by a rolling forecast generated by predictive analytics (Schnell 2019). This forecast, called PACE, draws on 60 data inputs from different sources such as World Bank, US Census, and ifo, to automatically predict revenue, contribution margin, fixed costs and EBIT. Interestingly, Stefan Schnell, Head of Corporate Controlling at BASF reported that those KPIs are estimated independently of each other. This means, they are not mathematically connected and do not add up. While this approach seems surprising at first, estimating each KPI independently has lead to more accurate forecasts.

Another example how technology can speed up analysis and thereby allow new insights is analytics for enterprise performance, e.g. with TRUFA (Deloitte 2019). TRUFA can draw on millions of transactions that the firm has available in their enterprise resource planning system and provides exploratory analyses to identify which potential performance drivers have the strongest statistical association with any KPI the controller or manager is interested in. Saving time is of the essence, because time is often the scarcest resource in the daily work of controllers and managers. Scholars like Robert Simons and Antonio Davila (1998: 71) have therefore coined the term "return on management [time]". Increasing automation and smarter algorithms promise a higher return for each minute used for analyses.

Process Mining is another example of innovative analyses of large amounts of data. Software such as Celonis, Processgold, or ARIS Process Mining can extract and subsequently visualize all transactions from the ERP system. Users can easily see within seconds, how difference processes for example procurement - have been done in the firm, and how long each process step takes on average, which allows Process mining also makes it very easy to identify specific processes that do not follow the norms. For 
example, if an invoice is scanned and put into a system although no purchase requisition item and no orders have been documented in the system, this may indicate a violation of corporate compliance policy. Drilldowns to the individual transaction make it possible to immediately identify the root-causes; for example on which days with which supplier did inefficient processes occur.

Self-service BI belongs to the array of new technologies available for controllers traditional tasks, providing managers with a direct window into the available business data and allowing them to directly use and/or manipulate these data as a direct input for decision-making and control (Lennerholt et al. 2018: 5056). It typically consists of a standardized data source which is available to all users, but can be complemented by other available data. The user interface of self-service Bl usually consists of a broad array of visual analytics tools, i.e., charts and diagrams, that can be individually composed to information dashboards and reporting packages on a real-time basis, adapting the reporting frequency to managerial information needs as well. Furthermore, access to self-service $\mathrm{BI}$ is available via mobile devices, allowing for increasing work flexibility. A variation of self-service $\mathrm{BI}$ is SAP's so-called digital boardroom which allows the simulation of different decision alternatives in real-time, thus bridging the gap between information technology and human cognition (Beverungen 2020: 226). Still, even though literature acknowledges increased user selfreliance as the main lever of self-service $\mathrm{BI}$, there is still evidence that in practice its implementation is hampered as non-technical and/or casual users in management need intensive and tailored trainings to benefit from its advantages (Lennerholt et al. 2018: 5060; Lamprecht and Seifert 2015: 51).

In addition to the types of technologies classified so far, there is a constant development of new tools that can automate and/or optimise some specific tasks in the finance function. Vyble, for example, offers an algorithm which - based on in-depth knowledge of German taxation rules - can automatically generate bundles of different employee-benefits that individually maximize the net salary for each employee (or minimize employers' total costs for a given net salary) (vyble 2020).

Summing up the contributions of these new technologies available for controllers' tasks, it is evident, that a large part of controllers' traditional work routines are already automated by bots and algorithms - or at least will be in the next years (Schäffer and Weber 2018: 7). The question therefore is, where are the blind spots of these digital technologies and how will controllers have to change their roles and tasks to fill this void.

\section{How do the roles and tasks of controllers change?}

Following up the year-long debate on controllers being service providers or business partners with no clear evidence yet that the transformation towards the latter has become common practice yet, the evolvement of controllers' roles seems to have picked up speed in the recent years. For 
example, in a recent survey Schäffer and Brückner (2019: 25) have identified nine different roles and 34 related competencies for future controllers. The most important roles attributed are business partner (as a proactive and strategic business consultant) and the guardian (with a focus on monitoring financial performance, risk behaviour and compliance). Surprisingly high ranks the new role of controllers as data engineers (who is responsible for data governance as well as the development of new tools in reporting, analytics or forecasting), compared to rather low rankings for a data scientists' role.

This differentiation in controllers' roles mirrors both the changes in firms' competitive environment as well as the requirements resulting from new technology: On the one hand, firm's competitive environment changing towards a VUCA world triggers an increasing amount of unique decisionmaking situations that have to be dealt with. On the other hand, digital technologies are not yet working on a stand-alone basis.

For example, the underlying algorithms are still what we would call in the best case weak Al, as they are only able to address standardized and welldefined situations (Bolander 2019: 851). For example, even a powerful machine-learning based algorithm in a predictive analytics system that has been trained to forecast revenue figures, cannot simply be transferred to do process mining tasks, even though in both cases pattern recognition per se is paramount. Additionally, even though large masses of "big" data have become available, it is by no means obvious per se, what information is embedded in these data, whether it is relevant and even more important, how it relates to a firm's business model and its performance-drivers. Making data become knowledge in this sense, as is oftentimes coined, or even wisdom, i.e., relate knowledge to soft ethical values, is a task that requires not so much algorithmic computing capacities, but rather human business acumen.

For controllers' tasks, this has important consequences. First, fewer and fewer controllers will be required for repetitive and clerical tasks, thus playing the traditional service provider role. In a recent survey among German managers and controllers, $66 \%$ suggested that "the digital financial sector will be much leaner in the future". At the same time $74 \%$ agreed that "the tasks of the finance department are increasingly shifting towards consulting tasks (for complex strategic issues or for the optimization of business processes)" (Firk et al. 2020: 25).

One important competency of future controllers is to identify new sources of performance measures. Currently, controllers typically focus on internal performance measures, such as financial KPIs and self-collected nonfinancial performance measures (such as customer satisfaction based on customer surveys). Potential new data sources include textual data from customer reviews, for example on Amazon; customer preferences in social media, employee satisfaction as expressed on websites such as glassdoor.com, employee generated KPIs such as completion rates of projects which become available in objectives and key results (OKR) solutions, information about political risks (Hassan et al. 2019) in the press and much more. While data scientist are often required to extract and analyse this type of data, controllers should actively monitor new developments and generate ideas which external data may help to make better informed business decisions. 
In addition to identifying new data, controllers also need to continuously adjust the performance measurement system to the changing demands. Referring to the three major economic trends discussed earlier, the following ideas may serve as examples to guide the development of new performance measures.

To be able to respond more quickly to new trends, KPIs need to be obtained more frequently. Instead of using monthly performance reports, interactive dashboards can be implanted that provide access to data in real time and allow drill-downs. At the same time, obsessive tracking of real time information should be avoided. For example, a substantial proportion of short term demand fluctuation is driven by idiosyncratic/random elements. Thus, checking sales data on a daily basis may not lead to new insights but just be a waste time. Of course, what exactly the right frequency is depends on the particular business and on the knowledge of specific events that may cause changes in the KPI. Another possibility to allow fast response while avoiding information overload is to automatically generate important KPIs very frequently, but only attract the attention of managers by notifications, if a KPI moves outside a pre-defined corridor the modern use of diagnostic controls (Müller-Stewens et al. 2020).

Innovative products and services should be approached with a trial-anderror mentality - which is a radical shift for many controllers who would like to see business plans with detailed ROI calculations. Given that ROI is difficult to estimate reliably for dynamic businesses, it is often better to track KPIs such as digital leads, click rates, customer growth, and customer engagement in regular intervals, set milestones and drop projects quickly if the targets for the milestones are not achieved.

Given that business success is more and more decided in the internet, it is also important to closely monitor the customer experience (for example, how many seconds and how many steps are necessary for a customer to open an account, verify his/her identity and place an order).

With respect to platform businesses, controllers should distinguish between metrics that are important if their firm is a user of a platform and metrics that are relevant if the firm is providing a platform. Firms, which offer products or services on different platforms, should monitor how many products are sent back by the customer (returns rate) on each sales channel, because the lack of personal interaction and buying advice can lead to higher return rates on platforms (Seiter und Autenrieth 2019). If the firm is providing the platform, it is important to track the number and quality of complementary products which are offered. For gaming consoles such as Nintendo, for example, the games developed by third parties are crucial for the customer's decision to buy the console. To achieve strong growth of complementary products, it can pay off to subsidize the development of those product and to charge only low royalties/commissions to third parties who want to offer their products on the platform. Once the platform is established in (or even dominates) the market, it can be time to reconsider these policies. The typical commission rate of large platforms such as the Google Play Store, the Microsoft Store, Apple's App Store, and others is $30 \%$ on most transactions (including in-app purchases) (Borck et al. 2020). For platforms referring to the Industrial Internet of Things (IIoT), such as MindSphere by Siemes, it is important to regularly check how many automation systems and smart meters are connected and how many services are offered by third parties via the IIoT (Speckmann und Horvath 2019). 
To adapt to the increasing customer preferences for sustainable products controllers should help to adjust operations, business models and the performance measurement system. Bosch, for example, expands its circular economy activities: for example, the remanufacturing of used car parts. Old parts are disassembled, worn components are replaced, and everything else - especially metal components - is cleaned and re-used. After re-assembly and testing, the remanufactured part has the same functionality and lifetime as a new one. Controllers need to support the development of such business models and can provide solutions, how the resulting cost savings can be distributed amongst the circular economy participants to motive all parties to participate (Lukassen 2020). AIDA Cruises, Germany's market leader in leisure cruises, has introduced a green controlling, which does not only measure KPIs such as water usage, energy consumption, and $\mathrm{CO} 2$ emissions, but also considers such KPIs for investment decisions (Arnaout 2019).

On top of the traditional competencies, an increasing ability to obtain and analyse data will be required in the future. As Adam Pradela explains, in the past, there was a clear division of labour between the team that did the programming work and obtained the data and the controller who analysed the data. In the future, these two tasks will merge more and more. Controllers will write their own code to retrieve the data and to analyse it. Moreover, advances in analytics tools also mean that experts can become more productive. Thus, the demand for skilled employees who conduct controlling related tasks will most likely increase. Or in the words of Mr. Pradela: "specialists and experts will also be in high demand in the future, especially in areas that related to management and control" (Schäffer und Pradela 2018: 18, our translation).

In times of big data and machine learning, it is of the essence that controllers keep the authority to understand the numbers best. Another important aspect is the increasing model complexity to improve predictions, for example with machine learning algorithms. If a controller does not know which sources generated the data and which strengths and weaknesses a certain algorithm has, he/she will cease to be the person that people listen to when they want to understand the financial analyses.

At the same time, the general trend towards data analytics represents a substantial opportunity for controllers to push for more fact-based decisions. While in the past, gut feeling might often have dominated over calculations due to a lack of data, new data sources and better IT put databased decision on stronger footage. More and more firms emphasize that they want do make decisions based on data. For example, Kasper Rorsted, CEO of Adidas, recently stated that historically, people at Adidas were shoemakers. Later, they were marketing people, now they are "data people" (Rorsted 2019).

Two developments will make this easier. First, many students in business and finance now learn basic programming (e.g. in Python or R) as part of the curriculum. Second, new tools emerge that make it easier to handle large data (such as Tableau) and to apply machine learning algorithms without programming knowledge (Hutson 2019). Uber, for example, has made their deep learning tool Ludwig freely available in the cloud ${ }^{6}$ and the

6 https://uber.github.io/ludwig/ 
MIT is developing a tool called Northstar. ${ }^{7}$ Still, while practitioners are strongly aware of this new challenge, a survey by Reißig-Thust (2018: 23), showed that professors and students of Controlling do not fully realize the importance of finding the relevant information in large amounts of data yet.

Finally, controllers should also get involved in estimating the value of customer data and ways to use such data in a responsible manner. It is currently an open question, how the value of data can be estimated for firms. While the value of digital advertising can be assessed relatively easy, the value of data to train machine learning models is highly uncertain. It might be substantially higher than the value for digital advertising. According to some estimations, the value of the data of a family of four persons may be up to $\$ 20,000$ per year in the future, if artificial intelligence will account for $10 \%$ of the economy (Lanier und Weyl 2018).

Summing up with a statement by Christian Schenk, CFO of MAN: „digitalization offers the opportunity to establish the financial organization as a real sparring partner for the management team in the long term. Digitalization has the ability to shift the focus from transactional activities to decision-making support [...] this also makes finance even more exciting as a field of activity with many career prospects, even in other areas of the company." (cited from Firk et al. 2020: 21).

Overall, we conclude that the new trends toward data analytics and agility represent an opportunity to generate more value for their organization. However, this requires to stay on top of the developments and to actively engage with new technologies.

\section{References}

Arnaout, A. 2019. Betriebswirtschaftliche Planung und Steuerung der GreenCruising Strategie bei AIDA Cruises. Controlling 31(6): 48-53.

Arnold, V. 2018. The changing technological environment and the future of behavioural research in accounting. Accounting \& Finance 58(2): 315339.

Baldvinsdottir, G., J. Burns, H. Nørreklit, R.W. Scapens. 2010. Risk manager or risqué manager. CIMA Research Executive Summaries Series 6(2): 1-10.

Bayus, B.L. 1994. Are product life cycles really getting shorter? Journal of Product Innovation Management 11(4): 300-308.

Bennett, N., G.J. Lemoine. 2014. What a difference a word makes: Understanding threats to performance in a VUCA world. Business Horizons 57(3): 311-317.

Beverungen, A. 2019. Executive Dashboard as a mediating technology of organization. In T. Beyes et al. (Eds.), The Oxford Handbook of Media, Technology, and Organization Studies. Oxford: 224-237.

7 https://northstar.mit.edu/ 
Blackburn, R. et al. 2015. A predictive analytics approach for demand forecasting in the process industry. International Transactions in Operational Research 22(3): 407-428.

Bolander, T. 2019. What do we loose when machines take the decisions? Journal of Management and Governance 23: 849-867.

Borck, J., J. Caminade, M. von Wartburg. 2020. Apple‘s App Store and Other Digital Marketplaces: A comparison of commission rates, July 22, 2020. [online]

https://www.analysisgroup.com/globalassets/insights/publishing/apple s_app_store_and_other_digital_marketplaces_a_comparison_of_commi ssion_rates.pdf. [31.07.2020].

Burns, J., G. Baldvinsdottir. 2005. An Institutional Perspective of Accountings' New Roles - The Interplay of Contradictions and Praxis. European Accounting Review 14(4): 725-757.

Byrne, S., B. Pierce. 2007. Towards a More Comprehensive Understanding of the Roles of Management Accountants. European Accounting Review 16(3): 469-489.

C3 Al. 2020. Software to accelerate your digital transformation. [online] https://c3.ai/ai-software/. [28.05.2020].

Crain, N.V., M.W. Crain. 2010. The Impact of Regulatory Costs on Small Firms. Report prepared for the Small Business Administration, Office of Advocacy. [online] https://www.sba.gov/sites/default/files/The\%20Impact\%20of\%20Regul atory\%20Costs\%20on\%20Small\%20Firms\%20(Full).pdf. [02.09.2020].

Davis, T.R.V., L.P. McLaughlin. 2009: Is finance a business partner yet? Strategic Finance 90(9): 35-40.

Deipenbrock, S., L. Landewee, G. Sälzer. 2019. Digitale Transformation des Controllings bei der Deutsche Post International. Potentiale und Herausforderungen durch Nutzung von Predictive Analytics. Controller Magazin 43(1): 45-50.

Delen, D., H. Demirkan. 2013. Data, information and analytics as services. Decision Support Systems 55(1): 359-363.

Deloitte. 2019. TRUFA. [online]

https://www2.deloitte.com/de/de/pages/technology/articles/trufaanalytics-application.html. [28.05.2020].

Devarajan, Y. 2018. A Study of Robotic Process Automation Use Cases Today for Tomorrow's Business. International Journal of Computer Techniques 5(6): 12-18.

Dörner, K., J. Meffert. 2015. Nine questions to help you get your digital transformation right. [online] https://www.mckinsey.com/businessfunctions/organization/our-insights/nine-questions-to-help-you-getyour-digital-transformation-right\#. [13.05.2020].

Economist (2016): The great divergence. [online] https://www.economist.com/united-states/2016/03/12/the-greatdivergence. [28.05.2020].

Economist. 2019a. [online] https://www.economist.com/business/2019/08/09/uber-lost-over-5bnin-the-second-quarter. [28.05.2020]. 
Economist. 2019b. Business and the effects of global warming. [online] https://www.economist.com/business/2019/02/21/business-and-theeffects-of-global-warming. [28.05.2020].

Ewert, R., A. Wagenhofer. 2007. Management Accounting Theory and Practice in German-Speaking Countries. In C.S. Chapman, A.G. Hopwood and M.D. Shields (Eds.), Handbook of Management Accounting Research. Vol. 2, London: 1035-1069.

Firk, S., R. Kuhr, M. Wolff. 2020. Digitalization of the Finance Function in the Automotive Industry: Results of an empirical study about the implementation status and challenges. [online] https://www.mhp.com/en/company/studies\#!studies-and-whitepapers-at-a-glance. [31.07.2020].

Frey, C.B., M.A. Osborne. 2017. The future of employment. How susceptible are jobs to computerisation? Technological Forecasting and Social Change 114: 254-280.

Friedman, T.L. 2006. The world is flat. The globalized world in the twentyfirst century. London.

Gänßlen, S., P. Prey. 2013. Green Controlling @ Hansgrohe. Controlling 25(6): 326-331.

Goretzki, L., E. Strauß, J. Weber, J. 2013. An institutional perspective on the changes in management accountants' professional role. Management Accounting Research 24(1): 41-63.

Granlund, M., K. Lukka. 1998. Towards increasing business orientation: Finnish management accountants in a changing cultural context. Management Accounting Research 9(June): 185-211.

Grönke, K. 2017. Die digitale Finanzorganisation. Zielbild 2025. Presentation on the ICV Annual Conference, Munich.

Grunwald-Delitz, S., U. Schäffer, J. Weber, J. 2014. Wie viele Controller gibt es in Deutschland? Controller Magazin 38(3): 48-52.

Hassan, T. A., S. Hollander, L. van Lent, A. Tahoun. 2019. Firm-level political risk: Measurement and effects. The Quarterly Journal of Economics 134(4): 2135-2202.

Heupel, T., V.W. Lange. 2019. Wird der Controller zum Data Scientist? In B. Hermeier, T. Heupel und S. Fichtner-Rosada (Eds.): Arbeitswelten der Zukunft. Wiesbaden: 201-222.

Holger, D. 2020. Danone pledges $\$ 2.2$ billion climate plan. [online] https://www.marketwatch.com/story/danone-pledges-22-billionclimate-plan-2020-02-26-64852256. [13.03.2020].

Hopper, T. M. 1980. Role conflicts of management accountants and their position within organisation structures. Accounting, Organizations and Society 5(4): 401-411.

Hutson, M. 2019. Bringing machine learning to the masses. Science 365(6452): 416-417.

Kemper, J. 2013. Zalandos rasantes Wachstum mit effizientem Controlling. Controlling \& Management Review 57(4): 46-51. 
Kokina, J., T.H. Davenport. 2017. The Emergence of Artificial Intelligence: How Automation is Changing Auditing. Journal of Emerging Technologies in Accounting 14(1): 115-122.

Lacity, M.C., L.P. Willcocks, A. Craig. 2015. Robotic Process Automation at Telefónica O2. Working Paper 15/02 (The Outsourcing Unit Working Research Paper Series).

Lamprecht, A., A. Seifert. 2015. Self-Service Reporting. Ist Ihre Organisation bereit dafür. Controller Magazin 39(6): 48-52.

Lanier, J., E.G. Weyl. 2018. A Blueprint for a Better Digital Society. Harvard Business Review Digital Articles 26(September): 2-18.

Lueg, K.-E. 2019. Digitalisierung in Finance Shared Services Siemens. Guest lecture at the WK Rech Accounting Conference, February 2019.

Lukassen, P. 2020. Bosch insights to capitalise on circular economy. [online] https://www.blumorpho.com/bosch-insights-to-capitalise-oncircular-economy/. [13.03.2020].

Manutiu, S. 2018. Digitalisierung im Controlling - Mehrwert durch Robotic Process Automation. Controlling 30(3): 4-10.

McCann, D. 2016. Robots, Robots Everywhere. CFO Magazine 32(7): 3438.

Müller-Stewens, B., S.K. Widener, K. Möller, J.C. Steinmann. 2020. The role of diagnostic and interactive control uses in innovation. Accounting, Organizations and Society 80: 1-21.

Newman, M., C. Smart, I. Vertinsky. 1989. Occupational Role Dimensions: The profession of management accounting. British Accounting Review 21(2): 127-140.

Oracle. 2019. Oracle Autonomous Database Technical Overview. [online] https://www.oracle.com/de/a/ocom/docs/database/oracle-autonomousdatabase-technical-overview.pdf. [28.05.2020].

Reißig-Thust, S. 2018. Controller-Kompetenzen in Praxis und Lehre. Controlling \& Management Review 62(6): 20-31.

Roehl-Anderson, J.M., S.M. Bragg. 2005. The Controller's Function. The Work of the Managerial Accountant. 3rd ed., New Jersey.

Rorsted, K. 2019. Creating value through purpose. Guest lecture at Frankfurt School of Finance \& Management, 17.09.2019.

Salesforce. 2020. EINSTEIN Your Smart CRM Assistant. [online] https://www.salesforce.com/content/dam/web/en_us/www/documents/ datasheets/einstein-cheatsheet.pdf. [28.05.2020].

Sathe, V. 1982. Controller Involvement in Management. Englewood Cliffs.

Sathe, V. 1983. The Controller's Role in Management. Organizational Dynamics 11(winter): 31-48.

Schäffer, U., L. Brückner. 2019. Rollenspezifische Kompetenzprofile für das Controlling der Zukunft. Controlling \& Management Review 63(7): 1431.

Schäffer, U., A. Pradela. 2018. Das Mindset muss sich verändern. Controlling \& Management Review 62(6): 12-18. 
Schäffer, U., J. Weber. 2018. Digitalisierung ante portas. Controlling 30(Special Issue): 4-11.

Schnell, S. 2019. Digitalization at Finance \& Controlling in BASF-from Business Partnering and Pathfinding. Key note speech at the 2019 Annual Conference for Management Accounting Research (ACMAR), Vallendar, 07.03.2019.

Seiter, M., P. Autenrieth. 2019. Steuerung plattformbasierter Geschäftsmodelle - Benötigen wir neue Steuerungsgrößen? Controlling 31(6): 11-17.

Simon, H.A., H. Guetzkow, G. Kozmetsky, G. Tyndall, G. 1954. Centralization vs. Decentralization in Organizing the Controller's Department. Houston/Texas.

Simons, R., A. Davila. 1998. How high is your return on management. Harvard Business Review 76(1): 70-80.

Speckmann, C., P. Horváth. 2019. Mit MindSphere die digitale Transformation vorantreiben. Controlling 31(6): 63-65.

Toepfer, T. 2020. Controlling in Cyclical Industries - Covestro Approach. Key note speech at the 2020 Annual Conference for Management Accounting Research (ACMAR), Vallendar, 05.03.2020.

Vasarhelyi, M. A., A. Kogan, B.M. Tuttle. 2015. Big Data in Accounting: An Overview. Accounting Horizons 29(2): 381-396.

Vyble. 2020. Innovatives Vergütungsmanagement. [online] https://www.vyble.io/. [31.07.2020].

Wade, M., J. Loucks, J. Macaulay, A. Noronha. 2016. Strategies for responding to digital disruption. Insights@IMD, No. 59.

Wagenhofer, A. 2006. Management Accounting Research in GermanSpeaking Countries. Journal of Management Accounting Research 18: 119.

Weber, J., U. Schäffer, U. 1998. Controlling-Entwicklung im Spiegel von Stellenanzeigen 1990-1994. Kostenrechnungspraxis 42(4): 227-233.

Weber, J., U. Schäffer. 2008: Introduction to Controlling. Stuttgart.

Weber, J., D. Stein. 2019. Online-Controlling - Eine kurze Einführung. Zeitschrift für Controlling \& Management 63(1): 22-28.

Weißenberger, B. E. 2019. Künstliche Intelligenz und das Innovator's Dilemma. Frankfurter Allgemeine Zeitung. 28.02.2019, 23: 18.

Wolf, S., B.E. Weißenberger, M.C. Wehner, R. Kabst. 2015. Controllers as business partners in managerial decision-making. Journal of Accounting and Organizational Change 11(1): 24-46.

Yahoo Finance. 2019. [online] https://finance.yahoo.com/quote/UBER/?guccounter=1\&guce_referrer= aHR0cHM6Ly93d3cuZ29vZ2xlLmNvbS8\&guce_referrer_sig=AQAAAJTFCJ RJ3Qx7Fx-

Afh7u9zMfmM_HjQMMHIAF_gK_WKO0T6zilmNBMBbAil100b3JGA0F1PY pTBkoM6uyLeU371-

gqxOkpNkGlvtdXRt5xHDSovQ7Dq9y4mJtOrO2_5v1DofXgtekcs-KdTNe1pq8ulmvJLOMlg4KYphRMgBkbzK. [08.11.2019]. 
Zetsche, D. 2015. [online] https://www.gruenderszene.de/automotivemobility/daimler-zetsche-autohersteller?interstitial. [09.11.2019].

Zoni, L., K.A. Merchant. 2007. Controller involvement in management: An empirical study in large Italian corporations. Journal of Accounting and Organizational Change 3(1): 29-43. 